\title{
Analysis of the material configurations and influence on the dynamic response
}

\author{
Zuzana Murčinková ${ }^{1, *}$, Michal Halapi ${ }^{1}$ \\ ${ }^{1}$ Faculty of Manufacturing Technologies, Department of Designing and Monitoring of Technical \\ Systems, Bayerova 1, 08001 Prešov, Slovak Republic
}

\begin{abstract}
The paper presents the analysis of the material configuration of composites based on the measurement of their dynamic response. The article presents the measurement scheme, the design of the measuring stand together with the analysis of the results. Moreover, it analyses the FFT spectrums of layered long fibre composite, short fibre composites of different fibres materials and homogeneous materials as steel and aluminium alloy.
\end{abstract}

Keywords: natural frequency, damping time, fibre, sample, measuring stand

\section{Introduction}

Each mechanical system (e.g. production machine-tool) under a particular type of dynamic force provides the dynamic response characterized by specific behaviour depending on various factors. The objective of the machine-tool designer is to maximize the dynamic stiffness between tool centre point-workpiece and tool centre point-drive motors while keeping the machine mass light for high speed positioning and high-productivity machining [1]. A broad variety of materials can be found in modern machine tool structures ranging from steel and cast iron to fibre reinforced composite materials [2]. The (short, long) fibre composite materials provide wide options of various material configurations regarding fibre volume fraction, fibre length, fibre orientation in bulk, laminate layer orientation etc. The fibre direction relative to the structure internal force flows has to be considered carefully during structural design [3]. The paper is contribution to research of dynamic characteristics (natural frequencies, material damping) of material configuration in case of low velocity impact intending for utilization in machine-tool applications mainly by experimental, also by numerical approaches.

\section{Measuring setup}

Fig. 1 illustrates the measuring chain. The measuring equipment is Polytec IVS 400. The main advantage is contactless and wear-free measurement what eliminates the influence of environmental conditions regardless some servo-mechanisms or noise protection to perform the measuring. Polytec is precise and reliable vibrometer based on a phenomenon of

\footnotetext{
* Corresponding author: zuzana.murcinkova@tuke.sk

Reviewers: Vladimir Dekýš, Alžbeta Sapietová
} 
Doppler Shift in laser beam to measure e.g. the vibration velocity, amplitude of a moving object etc. The light beam is reflected by moving surface and thus the frequency of light is shifted proportionally to its velocity. The laser-Doppler vibrometry is significant by the independence of measured data on reflected light intensity. Hence, the laser vibrometer is suitable for surfaces of low reflectivity.

If a wave is reflected by a moving object and detected by a measurement system, the measured frequency shift $f_{\mathrm{D}}$ (Doppler frequency) of the wave can be described as:

$$
f_{D}=\frac{2 \cdot v}{\lambda}
$$

where $v$ is the velocity of measured object and $\lambda$ is the wavelength of the emitted wave (of laser light beam). To be able to determine the velocity of an object, the (Doppler-) frequency shift has to be measured at a known wavelength. This is done using a laser interferometer. The optical interference, requiring two coherent light beams, with their respective light intensities $I_{1}$ and $I_{2}$, to overlap. The resulting intensity is not just the sum of the single intensities, but is modulated according to the formula:

$$
\mathrm{I}(\mathbf{r})=\mathrm{I}_{1}+\mathrm{I}_{2}+2 \sqrt{\mathrm{I}_{1} \mathrm{I}_{2}} \cos \left(2 \mathbf{k}^{\prime \prime} . \mathbf{r}+2 \Delta \phi\right)
$$

with a so-called "interference" term. This interference term relates to the path length difference between both beams, $\mathbf{r}$ is position vector, $k$ is wave number related to $\lambda$ :

$$
k=\frac{2 \pi}{\lambda}
$$

and thus $\mathbf{k}$ is wave vector, vector size is the same as size of wave number $k$ and vector direction is the same as direction of wave propagation. Superpositioning of two waves, the wave vectors $\mathbf{k}_{1}$ and $\mathbf{k}_{2}$ are needful to be known ( $\theta$ is angle between vectors), then after the decomposition to individual rectangular components where:

$$
\begin{aligned}
& \mathbf{k}^{\prime}=\frac{\mathbf{k}_{1}+\mathbf{k}_{2}}{2} \\
& \mathbf{k}^{\prime \prime}=\frac{\mathbf{k}_{1}-\mathbf{k}_{2}}{2}
\end{aligned}
$$

Then size of vector $\mathbf{k}^{\prime \prime}$ is:

$$
\left|\mathbf{k}^{\prime \prime}\right|=\frac{2 \pi}{\lambda} \sin \frac{\theta}{2}
$$

Physical description of Polytec equipment is according to [4, 5].

Some technical data: operating temperature $+5 \div+40^{\circ} \mathrm{C}$; velocity ranges: $\pm 20,100$, $500 \mathrm{~m} . \mathrm{s}^{-1}$; frequency range: $0 \div 22 \mathrm{kHz}$ (digital output), weight: $2.6 \mathrm{~kg}$. More in [4]. 


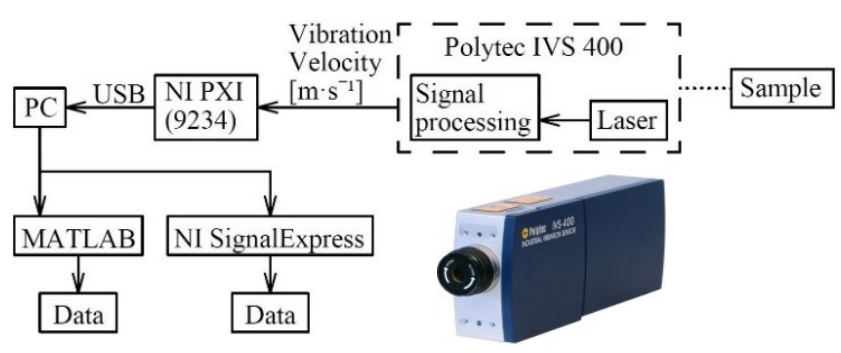

Fig. 1. Measuring chain with Polytec IVS 400

The samples were fixed on one side and excited by impulse force generated by steel ball of specific weight. The ball was rolling at inclined track of specific length.

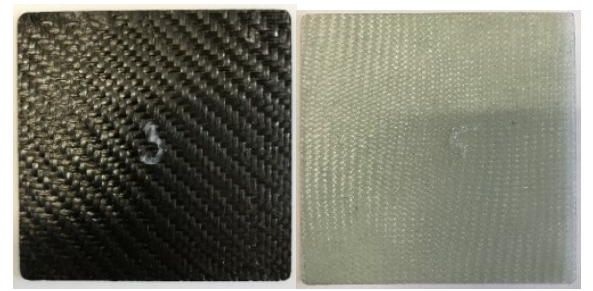

Fig. 2. Laminate with carbon (C\#X\#) and glass fibres (IGXXX)

The measurement was performed on six square laminate samples, size $115 \times 115 \times 0,9$ $\mathrm{mm}$, each of which is composed of three layers of carbon or glass fiber twill fabrics in matrix (Fig. 2). The carbon and glass fibre laminate samples are numbered as 1, 2, 3 and 4, 5,6 , respectively. The orientation of individual layers is different (Table 1) to be able to analyse the influence of that orientation. The carbon fabric is twill weave labelled as $200 \mathrm{~g} / \mathrm{m}^{2}$, twill $2 / 2$ and glass fabric $280 \mathrm{~g} / \mathrm{m}^{2}$, twill $2 / 2$, respectively. The three layers are in mixture of epoxy resin (EPIKOTETM Resin MGS ${ }^{\circledR}$ LR 285) and fixative (EPIKURETM Couring Agent MGS ${ }^{\circledR}$ LH286) of mutual ratio 10:4.

Table 1. Sample Layup description

\begin{tabular}{|c|c|c|c|c|c|c|c|c|c|}
\hline $\begin{array}{c}\text { Number of } \\
\text { sample }\end{array}$ & \multicolumn{3}{|c|}{$1(4)$} & \multicolumn{3}{c|}{$2(5)$} & \multicolumn{3}{c|}{$3(6)$} \\
\hline Layer & 1 & 2 & 3 & 1 & 2 & 3 & 1 & 2 & 3 \\
\hline $\begin{array}{c}\text { Fabric } \\
\text { orientation }\end{array}$ & $\#$ & $\#$ & $\#$ & $\mathrm{X}$ & $\mathrm{X}$ & $\mathrm{X}$ & $\#$ & $\mathrm{X}$ & $\#$ \\
\hline
\end{tabular}

Note: \# - fiber orientation parallel to the edges of the sample, $\mathrm{X}$ - diagonal fiber orientation $\left(45^{\circ}\right)$

The samples are under the low velocity impact in range $1.5-2.5 \mathrm{~m} / \mathrm{s}$. There is not one general definition with clear distinction between low and high velocity impact. The many researchers recognize the low velocity impact in case of velocity up to $10 \mathrm{~m} / \mathrm{s}$. Other researchers insisted that the upper limit of low-velocity impact vary from 1 to $10 \mathrm{~m} / \mathrm{s}$ depending on the material properties of target and the mass and stiffness of impactor. More in [6].

The proposed design of the measuring stand (Fig. 3) defines a position-adjustable measuring stand. Priority has been proposed for the research (testing, measurement) of behavior of composite materials - natural frequencies, shapes and damping factors. When designing the stand, consideration was given not only to the variety of materials but also to 
the shape and size of the samples to be measured - flat samples up to about $700 \mathrm{~mm}$ height and width and rotating shapes up to a diameter of $125 \mathrm{~mm}$, it is possible to measure essentially any shape of the sample if it is possible to clamp it in the clamp of measuring stand. Stand is of rigid construction but with the ability to adjust the various positions needed for measurement purposes. Fig. 3 shows the snapshot of impact of ball into sample.
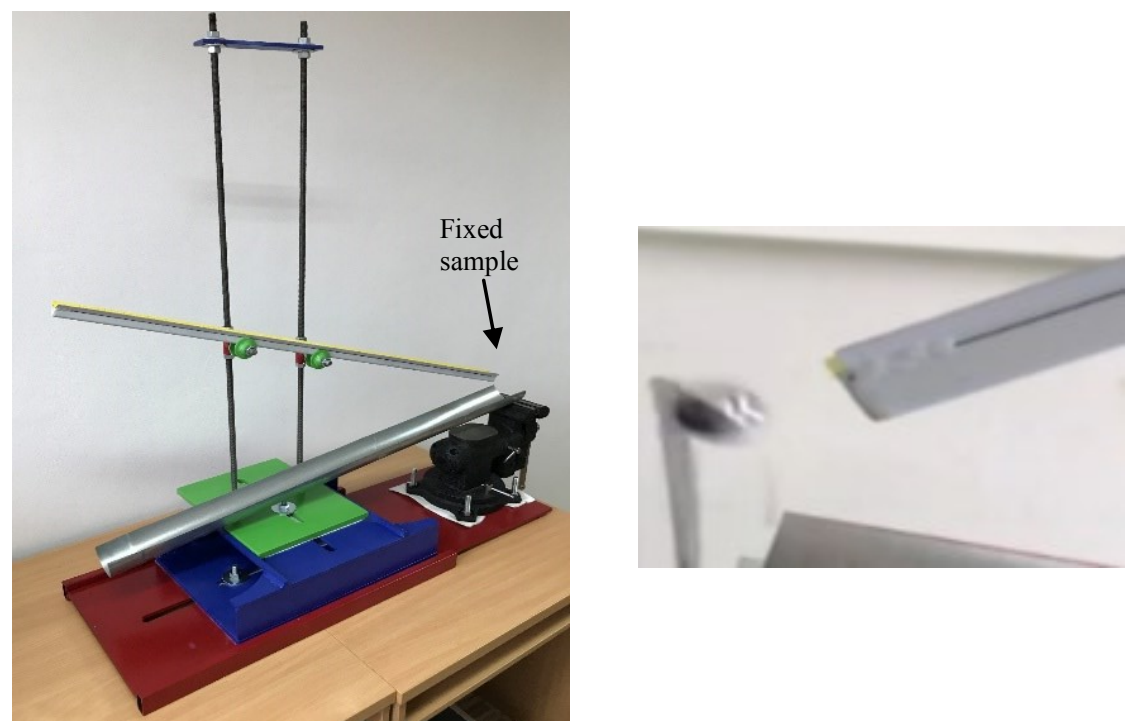

Fig. 3. Measuring stand and detail of impact

\section{Experimental results}

The graph in Fig. 4 evaluates the measured first two natural frequencies of samples based on the FFT (Fast Fourier Transformation) analysis of the measured vibration velocity values. Samples 1 (4), 2 (5), 3 (6) are of same carbon (glass) fiber, same matrix material, weight, number of layers, dimensions. The difference is only in material configuration. In this case it is different orientations of laminate layers and thus the different orientation of material properties. The impact forces are of four values: $332 \mathrm{~N}, 680 \mathrm{~N}, 2917 \mathrm{~N}$ and 5978 $\mathrm{N}$. The applied values of impact forces has not important influence for evaluation of natural frequencies of individual samples. The differences are changing in very small range. It is caused by both the material configuration and the measuring error. We can stated that material configuration has not significant influence on natural frequency.

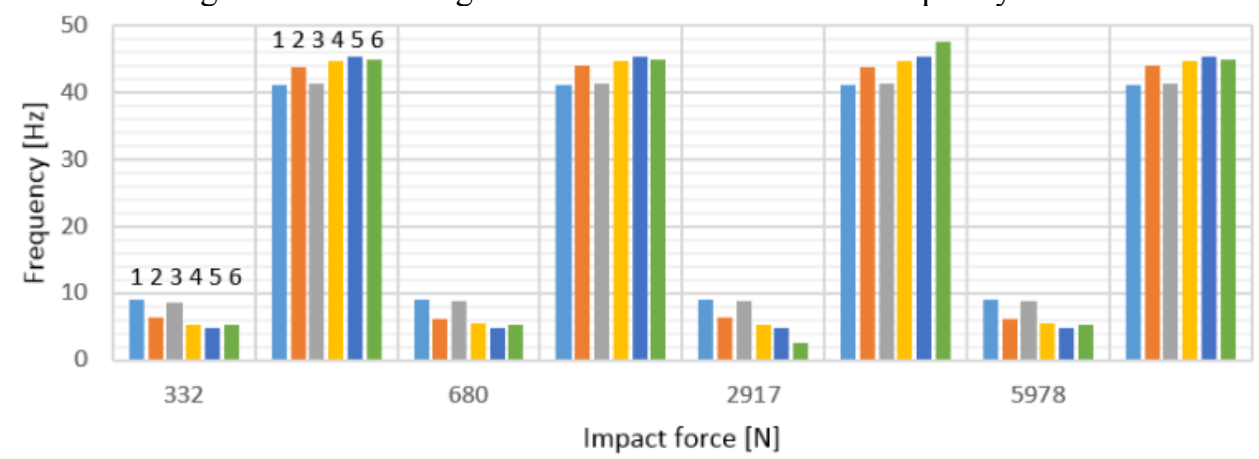

Fig. 4. The natural frequencies for 6 samples according to Table 
The samples of different material configuration are of different material damping time (Fig. 5). Naturally, the damping time of carbon laminate fibers is shorter comparing to glass fibers while the weight is lower. The longest damping time is for samples numbered $3(2 \mathrm{~s})$ and $6(2,3 \mathrm{~s})$ that have confiuration \#X\#. The shortest damping time is for samples numbered $2(1,3 \mathrm{~s})$ and $5(1,5 \mathrm{~s})$ that have configuration XXX. We can make statement that the material configuration influencing more damping time as natural frequency.

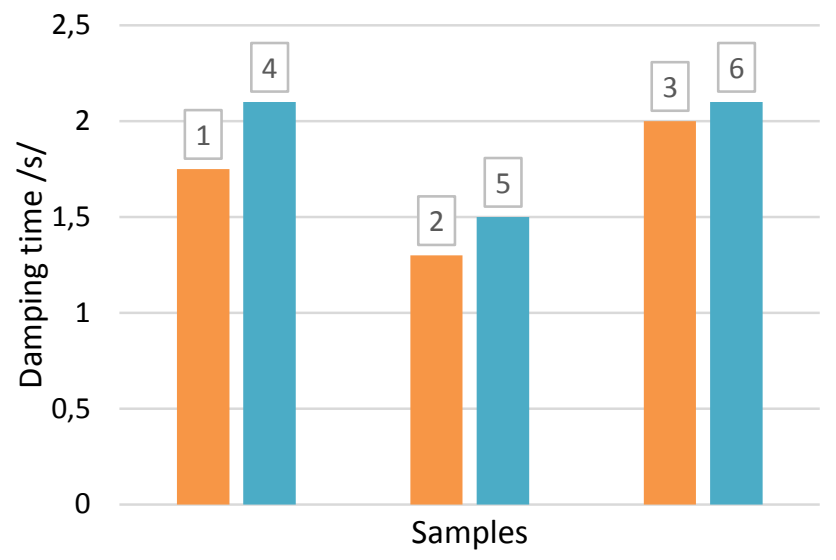

Fig. 5. Damping time for individual samples and same impact force

The measurements shows the different damping time of individual layers (Fig. 6). The circles in Fig. 6 marks the jumps (of various size) that are caused by change of wave phase. In generally, the reason of the phase change is interface layer-layer improving the damping.
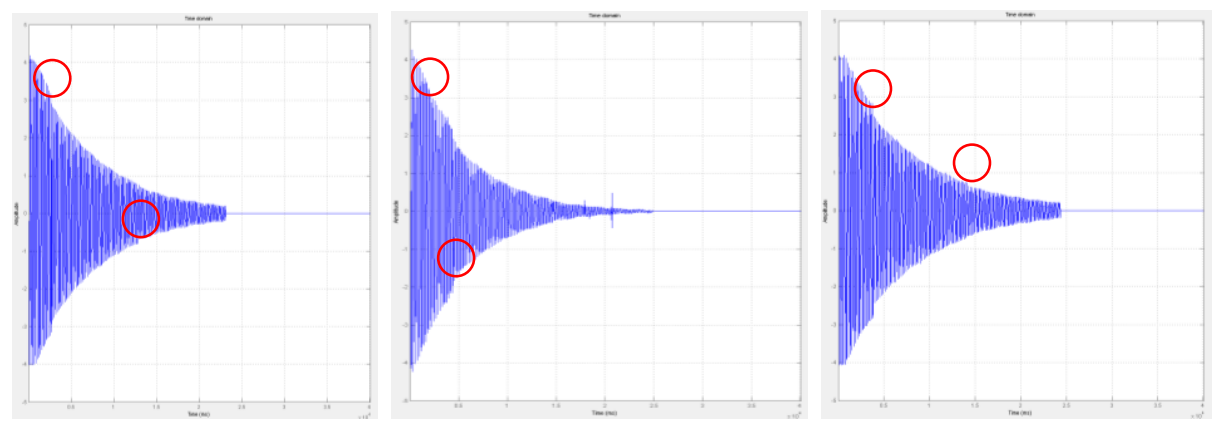

Fig. 6. Vibration velocity behaviour; dependence of vibration velocity amplitude on time for glass fiber laminate samples

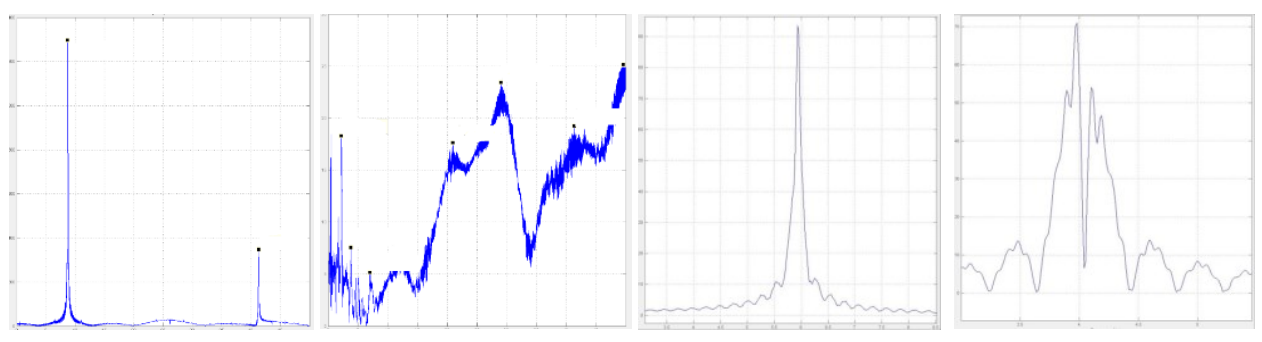

a)

b)

c)

d)

Fig. 7 FFT spectrum of layered long fibres (laminate), (a), short fibre composite (b), steel (c) and aluminium alloy (d); frequency vs. magnitude 
Evaluating and observing the results, we can make statement that dynamic response of homogenous and non-homogeneous (composite) materials is different (Fig. 7). Natural frequency of layered laminate and steel is characterized by one sharp peak (Fig. 7a, 7c) comparing to several peaks of short fibre composite (Fig. 7b) and aluminium alloy (Fig. 7d) that form the wide frequency range without significant frequencies. Such materials is appropriate for dynamic performance no matter how homogeneous is material. Homogeneity is only the idealization.

The experimental results were confirmed by numerical simulation in Abaqus/CAE software that involve simulation of laminates (similar to Ansys Composite PrepPost, Creo Simulate, Autodesk Simulation Composite Design) based on principle of Classic Laminate Theory. The boundary conditions of numerical model responded to real conditions. The material properties of individual laminate layer were defined according to provided data of manufacturer of samples. The twill was idealized and one twill layer was replaced by two layers of half thickness and orientation of fibres was defined perpendicular to each other. This way one layer was modelled. (More in [7]) The maximum difference between the experimental and numerical results is $0.2 \mathrm{~Hz}$.

\section{Conclusions}

The material configuration influence the final dynamic mechanical material properties. Our experiment were made on continuous fibre reinforced carbon and glass laminates as available materials with possibility to alternate material configurations. The material damping and natural frequencies were influenced by material configuration. In our experiment the configuration of XXX ( $45^{\circ}$ angle) provide the best material damping, lower first natural frequency (higher second natural frequency). These results are outcomes for other research of material configuration of composites and other construction materials regarding their various FFT spectrums.

Authors thank for supporting this research by grant VEGA 1/0910/17 of Agency of Ministry of education of Slovak Republic.

\section{References}

1. M. Law, Y. Altintas, A.S. Phani., Rapid evaluation and optimization of machine tools with position-dependent stability. Int. J. Mach. Tools Manuf. 68, 81-90 (2013)

2. H. Ch. Möhring et al., Materials in machine tool structures. CIRP Ann. - Manuf. Technol. 64 (2), 725-748 (2015)

3. J. E. Ashton, Implications of the Behavior of Advanced Composite Materials. J. Franklin Inst. 290 (6), (1970)

4. www.polytec.com

5. F. Trebun̆a et al., Experimentálne metódy mechaniky - laserová vibrometria a ESPI. (TU Košice, 2015)

6. Z. Shen, Characterisation of Low Velocity Impact Response in Composite Laminates. (University of Hertfordshire, PhD Thesis, 2014)

7. Z. Murčinková, M. Halapi, Micro-mechanical response of continuous and discontinuous fiber composites with support of computational software. Int. J Innovative Sci., Eng. Technol. 3 (1), 300-304 (2016) 